OPEN ACCESS

Edited by:

Mariona Portell,

Autonomous University of Barcelona,

Spain

Reviewed by:

Laszlo Hunyadi,

University of Debrecen, Hungary

Craig Haen,

New York University, United States

Giulia Bassi,

University of Padua, Italy

*Correspondence:

Mariella Venturella

venturella.mariella@gmail.com

Specialty section:

This article was submitted to

Quantitative Psychology

and Measurement

a section of the journal

Frontiers in Psychology

Received: 05 October 2018

Accepted: 24 July 2019

Published: 08 August 2019

Citation:

Venturella $M$, Carbonell X Cabré V and Arias-Pujol E (2019) A

Psychoanalytical Perspective on the Co-therapeutic Relationship With a Group of Siblings of Children With Autism: An Observational Study of Communicative Behavior Patterns.

Front. Psychol. 10:1832

doi: 10.3389/fpsyg.2019.01832

\section{A Psychoanalytical Perspective on the Co-therapeutic Relationship With a Group of Siblings of Children With Autism: An Observational Study of Communicative Behavior Patterns}

\author{
Mariella Venturella ${ }^{1 *}$, Xavier Carbonell', Víctor Cabré1 and Eulàlia Arias-Pujol ${ }^{1,2}$ \\ ${ }^{1}$ FPCEE Blanquerna, Ramon Llull University, Barcelona, Spain, ${ }^{2}$ Training and Research Center, Carrilet, Barcelona, Spain
}

A child diagnosed with autism may have a negative psychological and behavioral impact on their siblings, whose participation in a group with children in the same situation is a preventive measure. Our group study was conducted by two therapists (T1 and T2) assigned to co-therapy (CT) work. Both therapists shared the theoretical bases and understanding of the group and the needs of the individual subjects, and complemented each other in terms of the direction of their interventions, given that shared impressions and continuous exchanges that integrate countertransference aspects are essential to successful co-therapy. The objectives of this study were as follows: (a) to detect patterns of clarification, confrontation, and interpretation interventions by T1 and T2 in the group; and (b) to detect patterns of clarification, confrontation and interpretation interventions considering T1 and T2 as the only focal subject of the CT. Design was mixed-methods based on systematic observation, for which we developed a qualitative ad hoc instrument that combined a field format and a categorizing system. Interobserver agreement was analyzed quantitatively using Cohen's kappa and Krippendorf's canonical concordance. Once data reliability was confirmed, lag sequential analysis using GSEQ5 software was performed to search for behavior patterns. The results show (a) different behavior patterns in the clarification, confrontation, and interpretation interventions by $\mathrm{T} 1$ and $\mathrm{T} 2$; and (b) different behavior patterns when T1 and T2 are considered as the focal subject (CT). Our study offers a new perspective on the impact of therapist interventions on participants in this kind of group.

Keywords: co-therapy, siblings, autism spectrum disorder, group psychotherapy, therapeutic communication, mixed method, systematic observation

\section{INTRODUCTION}

Family centered care in the autism spectrum disorder (ASD) field has attracted growing interest in the past decade in early care units (Gabovitch and Curtin, 2009; Christon and Myers, 2015). Studies focused on children with siblings with ASD (ASD-Sibs) have adopted different approaches. Hypothesizing genetic vulnerability (Cassel et al., 2007), a number of follow-up studies have 
sought to identify early stage ASD-Sibs predictors (Yoder et al., 2009). Another perspective has sought to identify the benefits of the sibling bond for autistic children, with a retrospective study reporting that older siblings positively influence the social skills of younger ASD-Sibs (Ben-Itzchak et al., 2018). In recent years, interest has grown in whether ASD-Sibs have a greater risk of developing emotional and behavioral problems than the general population, with empirical results pointing to enormous variability (Griffith et al., 2014; McHale et al., 2016): some studies affirm an increased risk (Meyer et al., 2011; Shivers et al., 2013; Hastings and Petalas, 2014), others suggest a similar risk (Macks and Reeve, 2007; Ferraioli and Harris, 2009; Walton and Ingersoll, 2015), and yet others argue that ASD-Sibs demonstrate better social adaptation and more positive sibling relationships (Hastings, 2003; Petalas et al., 2012). A recent meta-analysis (Shivers et al., 2018) of 69 studies that compared siblings with ASD-Sibs with siblings without ASD-Sibs found that, for some 800 individual comparisons, children with ASD-Sibs had significantly poorer - albeit small in magnitude - outcomes, specifically in their internalization of behavioral problems, psychological functioning, beliefs, social functioning, and relationships between siblings. No significant results were obtained for adaptation, externalization of behavioral problems, attention-deficit/hyperactivity disorder, coping or family functioning.

Support groups for ASD-Sibs are key to the prevention and early detection of developmental and emotional disorders and also in terms of therapeutic strategies when difficulties appear (Shivers et al., 2018). Traditionally, interventions for ASD-Sibs are implemented through support groups for family members, focused on communicative strategies that foster positive relations between siblings and a climate of trust in the family that facilitates the revelation of thoughts and feelings (Harris and Glasberg, 2003). Programs are available that seek to empower ASD-Sibs to stimulate and play with their siblings with autism and help them acquire social skills (Tsao and McCabe, 2010; Tsao et al., 2012). Since the behavioral problems frequently associated with ASD may lead to the emergence of negative emotions in the siblings (Tsao et al., 2012), some studies have underlined the need for siblings to be able to express feelings and thoughts (Mascha and Boucher, 2006; Angell et al., 2012), although - as if they recognize that there is no room in the family for further problems - ASD-Sibs often appear to have no difficulty in adapting and are understanding and responsible. However, it has also been observed that these children may deliberately hide their need for a space to be someone other than "the brother or sister of" their sibling (Centre Educatiu i Terapèutic Carrilet, Alcácer et al., 2013; Farrés, 2014).

The goal of our sibling support group is to offer a space where ASD-Sibs can freely express feelings and thoughts that may remain silenced in their everyday life or that may be perceived as contradictory. In the group the children explore the ambivalence of wanting to care for their sibling with special needs while also feeling guilt, anger and maybe even hate because of the special treatment their sibling receives from parents or at school. Figure 1 shows, as an example, an excerpt from a session in which
T2: What was it like at home with your brothers and sisters? Was it ok? Was it difficult?

P2: Not good for me.

T2: What happened P2? Do you want to tell us about it?

$\mathrm{T} 1$ drags the boxes of materials to part of the table where nobody is sitting.

P2: On Christmas Eve, I think it was ...

T2: What?

P2: We were left in the dark

T2: In the dark? Why, what happened?

P2: Because my brother wanted to turn off the light.

T2: Really?

T1: And what happened?

P1: I...

T1: Wait, it's important. And what happens if he wants to be in the dark? Must everyone be in the dark?

$\mathrm{P} 2$ nods his head.

T1: And couldn't you have supper or look at your presents?

P2: We could look at our presents. Yes.

P2: We could look at our pros
T1: Sure? But in the dark

P2: By candlelight.

T1: By candlelight.

T2: By candlelight.

T1: Why didn't your brother want the light on?

P2 shrugs his shoulders and hands in doubt.

T1: What happened if the light was on?

T2 looks at the camera and moves the boxes of materials closer to his side.

P2: Well, he asked for it to be turned off.

T2: If you turned it on, what happened? Could he have got very cross, or what? P2 nods his head.

T2: Wow!

T1: The whole family frightened and in the dark like that, it's very complicated.

T2: Wow, I guess so.

T1: It's very difficult.

T2: I suppose you must get a bit angry and say: 'Why does your brother want everyone here in the dark?'

P2 nods his head.

T2: What do you think? Have your brothers ever been as angry as P2's?

P4 nods her head.

P1: No.

T2: Look, P4 says yes.

P1: My sister, when she turns off the light, she wants to have a party. We had a thing that makes music. It's called Twister.

T1: Hmm.

T2: $\mathrm{Hmm}$.

P1: It is a thing that makes music, then she dances and turns off the light.

P4 nods her head.

T2: P4 knows. She's nodding her head.

T2 imitates P4 nodding her head.

T2: I know what it is.

P1: Yes.

T2: But, it makes your sister happy, right?

P1: Yes, it gives off light.

T2: Ok, but P2 says that when his brother wants to turn off the light, he's angry and makes the whole family.

T1: He doesn't want to see anyone.

T2: Exactly.

T1: He doesn't want to see anyone or anything.

T2: And P4 said that her brother got angry, sometimes, right?

P4: Yes.

T2: What happens? Do you want to tell us, like P2 did?

T1: What makes your brother angry, P4?

P4: When he's in my room ...

T2: Yes...

P2: Yes.... he wants to turn off the light.

T1: Wow

T2: You are in your room, and he wants to turn off the light?

P4 nods her head.

T1: That's a bit like P2's brother. There are times when he doesn't want to see anything.

T2: Of course. I suppose both of you have to put up with it.

$\mathrm{P} 2$ nods his head.

P4 nods her head.

T2: It's very tiring. It's worse than the homework we were talking about.

T2: It's very tiring. It's worse than the homework we were talking about.
T1: Homework is common, but I guess there's homework that families have, which is to adapt to your brothers and sisters and find a way to do things all the same. To find the way to light a candle. To find out whether P2's brother can put up with a candle or not. You've found a way that won't make him get cross and that isn't too bad for the rest of you.

P2 subtly raises his eyebrows.

T2: Perhaps this is something that your siblings have in common. That sometimes

things have to be exactly as they want, because if not, they get angry.

FIGURE 1 | Fourth group session transcriptions.

siblings are discussed (Centre Educatiu i Terapèutic Carrilet, Alcácer et al., 2013; Farrés, 2014).

In this research, we wanted to study the spontaneous interaction between children and psychoanalytical therapists 
in a group. This required a flexible methodology adaptable to all behaviors and contexts. Mixed methods research offers an excellent combination of rigor and flexibility while allowing qualitative and quantitative techniques to be used within the same paradigm (Creswell et al., 2003; Johnson et al., 2007; Tashakkori and Teddlie(eds), 2010). Indeed, qualitative and quantitative techniques are gradually progressing toward integration (Hesse-Biber and Johnson, 2013; Fetters and Freshwater, 2015; Onwuegbuzie et al., 2018), although some problems remain, such as how to achieve that integration (Bryman, 2007; Bazeley, 2012,2017 ) and its translation into practice (Onwuegbuzie and Leech, 2005; Happ et al., 2006). Mixed methods, which involve combining inductive logic with deductive logic (Bergman, 2010) throughout the entire research process, has an integral role to play in "complete" methodological development. Observational methodologies have been pioneering in achieving this methodological complementarity (Anguera et al., 2001; Anguera and Izquierdo, 2006; Sánchez-Algarra and Anguera, 2013), e.g., the recent conceptualization in indirect observation (Anguera et al., 2018).

The conceptual framework for this study gave rise to four essential dimensions reflected in the observation instrument: ASD-Sib, turn-taking, group, and play. However, although all the small children in the support group shared the fact of having a sibling with ASD, there were few explicit interventions about the sibling. Group activities focused on plasticine models and wooden doll families. The plasticine figures made by the children were kept, which led to some becoming characters in the group (Venturella et al., 2015).

In this mixed-methods study we focus on the group and turntaking dimensions of the therapists. From a psychoanalytical theory perspective, the group interventions of the therapists were divided into clarification (I1), confrontation (I2), and interpretation (I3). Clarification allows the therapist to emphasize essential elements in communications and perceptions, confrontation stimulates an interest in thinking, reflecting, and understanding behavior in relation to others, and interpretation is a hypothesis as to how a group participant may feel in the here and now of a session (Coderch, 2009; Ferro and Civitarese, 2016).

In this study we were especially interested in observing how the two therapists related and interacted as co-therapists with each other and with the children.

Co-therapy is very frequent in group work (Roller and Nelson, 1996), with advantages and benefits as follows: (a) co-therapy expands creativity and the range of interventions and techniques and so improves transfer and control of countertransference; (b) the therapists complement each other with their knowledge, skills and personalities, while still being able to adopt different positions; (c) the therapy process is improved and shortened; (d) there is mutual support and supervision; (e) responsibilities and decision-making are shared; and (f) the interaction between therapists facilitates the outsourcing of covert conflicts and ambivalence. Furthermore, co-therapy is a highly versatile tool that can be used in many ways and in numerous configurations (Kosch and Reiner, 1984; Hoffman and Laub, 2006). From a psychoanalytical perspective, co-therapy has been focused on pair therapy (Sommantico, 2016). In work with children and adolescents, however, and specifically in the ASD-Sibs setting, there is a research vacuum.

The Society of Group Psychology and Group Psychotherapy provides some arguments against psychotherapy groups conducted with a single therapist (Breeskin, 2013): (a) lone therapists, no matter their expertise, will likely fail to keep up with the richness of the group experience, expressed in non-verbal signals and parallel conversations, which are important details that are at risk of being lost; (b) lone therapists could fail to keep pace with the group's needs, harming themselves and the participants; and (c) lone therapists in charge of a group means offering professional practice without minimum reference values for the same participants. In short, a therapy partnership offers the opportunity to interpersonally shape a powerful model for the group of participants. A study of 54 co-therapy pairings found that predictors of satisfaction were aspects such as theoretical compatibility and differences in confrontation styles; also significant was being able to select the experience of working together in co-therapy (Bridbord and DeLucia-Waack, 2011). From our perspective, because of the complexity of the interactions, the group phenomenon and the co-therapy relationship, we focused our study on communication, specifically on the interventions and complementarity of the co-therapy relationship.

The training of the therapists is the solid foundation that ensures the studied group become therapeutic. Since the group in question is not a self-help group or a group with a specific requirement, but rather resembles a parent or family group, we may define it as a support group. Support groups, in contrast with ad hoc crisis intervention groups, are designed to offer emotional support to persons sharing a common problem or handicap (Scheidlinger, 2005). But unlike a standard support group working on the subject that links it, our intervention group reinforces individual and group work so that the therapeutic work is self-validated.

Also relevant here is Scheidlinger's idea of the mother-group, which refers to an aspect of identification with the group entity that connotes a covert wish of group members to restore a state of unconflicted well-being, characteristic of an earlier tie to the mother (Scheidlinger, 1974). This longing for a return to that relationship and its unequivocally positive need-gratifying elements is brought directly to bear in and by the group.

The main objective of our research was to study the interaction of therapists and children using a mixed methods framework, an approach that has acquired a certain tradition in recent years (Arias-Pujol and Anguera, 2017; Del Giacco et al., 2019), in accordance with the Guidelines for Reporting Evaluations Based on Observational Methodology (Portell et al., 2015). Specifically, we wanted to identify the existence of possible patterns of behavior in the communicative interactions between children and therapists (a) in turn-taking and (b) breaking down interventions involving clarification (I1), confrontation (I2), and interpretation (I3) for therapist 1 (T1) and therapist 2 (T2) separately and for the two therapists as a single focal subject (co-therapists, CT). 


\section{MATERIALS AND METHODS}

\section{Design}

The observational methodology offers eight types of observational designs (Anguera et al., 2011; Sánchez-Algarra and Anguera, 2013; Anguera and Hernández, 2015) based on three criteria: the number of participants (idiographic or nomothetic), the continuity of the recording (one moment or follow-up) and the number of criteria observed (unidimensional or multidimensional). The design of our research was N/F/M, i.e., it was nomothetic $(\mathrm{N})$ because we studied six subjects (two therapists and four children), it consisted of follow-up (F) because we transcribed six consecutive and multidimensional group sessions, and it was multidimensional (M) because we coded different dimensions of the observed behaviors with concurrent and event-base data from quadrant II of the systematic observation design.

\section{Participants}

The six participants were two women therapists (T1, T2) and four children aged 6-9 years old (P1, P2, P3, P4).

The therapists are clinical psychologists with decades of experience with groups and with autism from a psychoanalytical perspective, and T1, who is older than T2, is also a psychoanalyst.

Regarding the participating children, inclusion criteria were (a) age 6-9 years, (b) attendance at a standard school, and (c) having an ASD-Sib. Exclusion criteria were a diagnosis of pervasive developmental disorder (PDD) and attendance at psychotherapy. The therapists requested the permission of the parents to include their children in the group.

\section{Intervention Design}

The support group intervention was offered in Carrilet Education and Therapy Center (Barcelona, Spain), which specializes in the care of people with autism and their families. A sibling support group offers siblings a space where they can express their feelings and talk about issues in their relationship with the ADS-Sib without fear of hurting their parents. The group has both an educational and therapeutic focus. Autism is discussed with other children who are living a similar experience and with adults who are not members of the family. In words and through play, using plasticine, drawings, etc., the children express feelings, including fear, jealousy, anger, guilt, etc. The psychoanalytical therapists legitimize the ambivalence of the children's feelings and help them understand and contain their emotions. Through conversation and play these children share feelings that could easily be silenced within the family and this helps them develop their own differentiated identity (Fieschi et al., 2011; Venturella et al., 2014).

The setting is a 1-h monthly meeting over 2 years. Before each session, the therapists send a reminder letter to the children's home regarding the upcoming session. As material, the group uses two shared boxes, one with colored plasticine and the other with two foldable wooden figures of families (father, mother, girl, and boy), paper, colored crayons and pencils, rubbers, scissors, and a folder for drawings. The group's activities focus mostly on the wooden dolls and the plasticine, and the plasticine figures made by the children are kept, with some becoming like persons in the group.

At the family level, there are three meetings with parents, two in groups (one each before and after the main sessions) and an individual meeting (Fieschi et al., 2011; Venturella et al., 2014).

In accordance with the principles of the Declaration of Helsinki and the Ethical Code of the General Council of the Official College of Psychologists of Spain, the participants were informed that they were being filmed and parents signed a written informed consent, authorizing the participation of their children in this research. In relation to this study, on the first day of therapy, the reason for filming was explained to the subjects, along with the privacy and confidentiality conditions regarding session content. During the sessions, an observer (a psychologist in training) sat at a distance from the table where the group's conversation was taking place and took notes.

\section{Instruments}

We used both observation and recording instruments.

Our ad hoc observation instrument, following observational methodology canons (Sánchez-Algarra and Anguera, 2013; Portell et al., 2015), combined field format with category systems (Anguera and Izquierdo, 2006; Anguera et al., 2007) and was structured according to the dimensions identified from the conceptual framework. A system of categories was built from the dimensions, which was hierarchical in some of the dimensions (i.e., macro-categories that unfolded into categories). This instrument was designed to fulfill exhaustiveness and mutual exclusivity requirements for each of the category systems. For this reason, all verbal/vocal expressions by the children and the therapists were first transcribed in full. Their analysis resulted in an instrument of 27 codes in four dimensions: (1) turn-taking, (2) group, (3) ASD-Sib, and (4) play. The turn-taking dimension, which reflected turn-taking in speaking, was divided into two macro-categories: therapists and children. The group dimension, which considered the participatory interactions in each turn, was distributed in five macro-categories: body, sound, brief, relationship, and intervention. The ASD-Sibs dimension - the common element among the participating children - reflected all comments regarding the sibling with autism. Finally, play reflected the techniques used to foster interaction and expression within the group.

Figure 2 depicts the observation instrument with the dimensions along with a description of the macro-categories and codes (the number of the codes does not reflect range or quantity).

We focused on the intervention macro-category (the group dimension) and on specific communications between therapists in relation to the emotional field of the children. To better exemplify the data analyzed below, Figure 3 shows fragments of text that could potentially represent the intervention macrocategory (indicated in dark gray).

Used as the recording instrument - to ensure maximum accuracy in data collection - was a video camera. To minimize the reactivity bias of the participants, the camera was positioned discreetly at a high viewing angle in the room. 


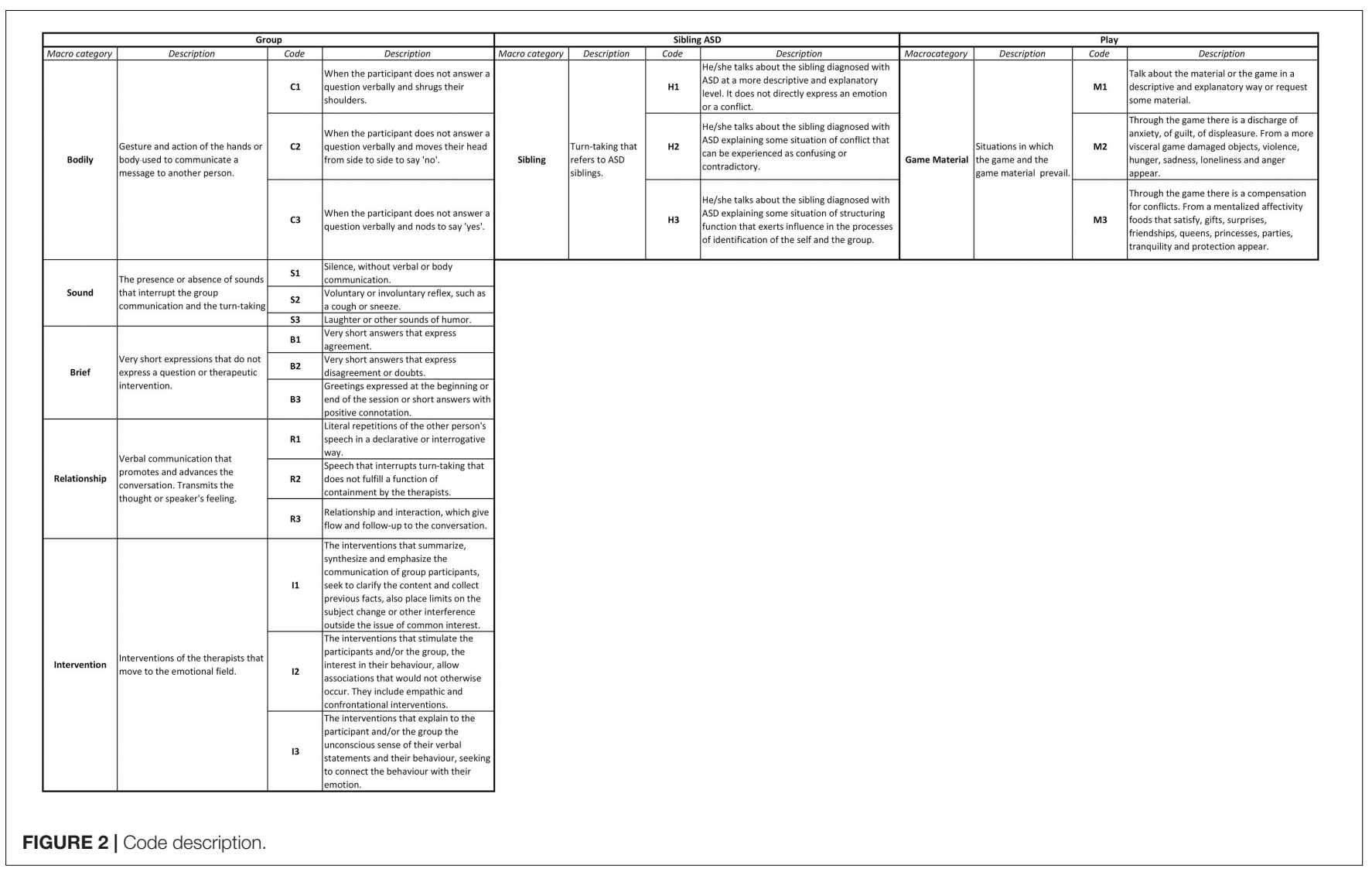

\section{Procedure}

For the purposes of this study, we used recordings of six sessions from the first year with the group, but excluded three of these as not being fully audible.

All sessions were video-recorded and subsequently transcribed in full. For the transcribed conversations between the children and the therapists, intervention turns were considered as the units of analysis, which were assigned the codes reflecting each dimension from the observation instrument.

\section{Data Quality Control: Interobserver Agreement}

Data quality control was implemented to ensure that codes were correctly assigned. Three observers, previously trained using the approach described by Anguera (2003), analyzed and coded two of the sessions.

Interobserver agreement was measured using Cohen's kappa (k) (Cohen, 1960, 1968), following Bakeman and Quera (1996, 2011), resulting in values of 90-97\% (rated as "very good agreement"). To discriminate interrelationships between the different observers and their standard errors, canonical concordance with a third observer was calculated (Anguera, 1997, 2003; Krippendorff, 2004, 2013), resulting in a Krippendorf's alpha $(\alpha)$ value of $96 \%$ (with values above $80 \%$ indicating reliable data). These values indicate that the categories were well defined and had good consistency, with the fact that the system was highly concordant guaranteeing the reliability of the material encoded for subsequent analysis.

\section{Data Analysis}

Since our goal was to detect the existence of possible patterns of behavior in communicative interactions between the therapists and the children, we used intersessional sequential analysis, considered to be the most suitable data analysis technique for our purposes. The sequential analysis technique, developed by Bakeman (1978) and Sackett $(1978,1979)$ more than 40 years ago, essentially detects whether certain stable behavioral patterns have a greater probability of occurrence than would be expected by chance (Bakeman, 1978; Bakeman and Gottman, 1989; Bakeman and Quera, 2011). Since sequential analysis detects hidden patterns, it is considered an excellent methodology for studying communication in psychotherapy research groups. It has proven to be especially suitable for studying changes that occur over sessions (Arias-Pujol and Anguera, 2004, 2005, 2017; Vaimberg, 2010, 2012; Arias-Pujol, 2011; Roustan et al., 2013; Del Giacco et al., 2019), as well as in families (Gimeno et al., 2006), education (Rodríguez-Dorta and Borges, 2017; García-Fariña et al., 2018), and sports (Lapresa et al., 2013).

In our study we applied it to an analysis of concurrent and event-based quadrant II data. For our analysis, we used GSEQ v.5.1 software (Bakeman and Quera, 2011), in which an algorithm compares the unconditional and conditional probabilities of behavioral occurrences (in our case, 
Text extracted from session 3 :

\begin{tabular}{|c|c|c|c|c|c|}
\hline Excel Line & TURN & TEXT & GROUP & S.ADS & PLAY \\
\hline 681 & $\mathrm{TE}$ & TE: PMi, is a nativity scene that has done? & R3 & $\varnothing$ & M1 \\
\hline 682 & PMi & PMi: Yes. & B3 & $\varnothing$ & $\varnothing$ \\
\hline 683 & TE & $\begin{array}{l}\text { TE: I thought now that you finish what you're doing, because it is our time to end this } \\
\text { meeting. }\end{array}$ & 11 & $\varnothing$ & $\varnothing$ \\
\hline 684 & & PMe pick up the dolls & $\varnothing$ & $\varnothing$ & $\varnothing$ \\
\hline 685 & PMe & PMe: Two... & R2 & $\varnothing$ & $\varnothing$ \\
\hline 686 & TN & TN: The father, sisters and mother. & 11 & $\varnothing$ & $\varnothing$ \\
\hline 687 & TE & $\begin{array}{l}\text { TE: See if there is a place for everyone to be nearby. At heart he is doing the PM. How do } \\
\text { you say? }\end{array}$ & 11 & $\varnothing$ & $\varnothing$ \\
\hline 688 & TN & TN: PMi! & R3 & $\varnothing$ & $\varnothing$ \\
\hline 689 & $\mathrm{TE}$ & TE: PMi... it's a family are all together. & 12 & $\varnothing$ & $\varnothing$ \\
\hline 690 & TN & TN: The cave. & 13 & $\varnothing$ & $\varnothing$ \\
\hline 691 & TE & TE: Nativity, and a family are all together. & 13 & $\varnothing$ & $\varnothing$ \\
\hline 692 & TN & $\begin{array}{l}\text { TN: We are not a family, but we are a group that we put together here to talk about things } \\
\text { that are important. }\end{array}$ & 12 & $\varnothing$ & $\varnothing$ \\
\hline 693 & PMe & PMe: Yes. & B3 & $\varnothing$ & $\varnothing$ \\
\hline 694 & TN & $\begin{array}{l}\text { TN: It's good have a families and groups that we can feel nearby and that allow us not to } \\
\text { feel invisible, right? }\end{array}$ & 12 & $\varnothing$ & $\varnothing$ \\
\hline 695 & $\mathrm{TE}$ & TE: Yes. & B3 & $\varnothing$ & $\varnothing$ \\
\hline
\end{tabular}

Text extracted from session 6 :

\begin{tabular}{|c|c|c|c|c|c|}
\hline Excel Line & TURN & TEXT & GROUP & S.ADS & PLAY \\
\hline 195 & TE & TE: And that is making doll, what's it, as they say. PMi has a name? & R3 & $\varnothing$ & M1 \\
\hline 196 & PMe & PMe: Yes or not? & R3 & $\varnothing$ & M1 \\
\hline 197 & TN & TN: The PMi is very quiet today. & 11 & $\varnothing$ & $\varnothing$ \\
\hline 198 & TE & TE: She is highly concentrated. & 12 & $\varnothing$ & $\varnothing$ \\
\hline 199 & TN & TN: She is as mysterious. & 13 & $\varnothing$ & $\varnothing$ \\
\hline
\end{tabular}

Text extracted from session 9:

\begin{tabular}{|c|c|c|c|c|c|}
\hline Excel Line & TURN & TEXT & GROUP & S.ADS & PLAY \\
\hline 741 & TE & TE: Of course, everyone is happy everyone is a little difficult. There are times that ... & 11 & $\varnothing$ & $\varnothing$ \\
\hline 742 & TN & TN: There is always a bit fear... & 12 & $\varnothing$ & $\varnothing$ \\
\hline 743 & TE & TE: $A$ bit of disgust. & 13 & $\varnothing$ & $\varnothing$ \\
\hline 744 & TN & $\begin{array}{l}\text { TN: As a bit like today, we had some violent messages, some messages of spring, there is } \\
\text { always a little bit of everything, of course. }\end{array}$ & 13 & $\varnothing$ & $\varnothing$ \\
\hline
\end{tabular}

FIGURE 3 | Transcription examples.

prospectively and retrospectively) in the form of frequencies of transition to a criterion behavior, established according to the objectives of the study.

Since the study refers to communication processes, in an initial analysis, we separately considered the intervention turns of the therapists (T1 and T2) and of the grouped children (children) as the criterion and conditional behaviors. In a second analysis, we separately considered the criterion behavior of each therapist for the three forms of intervention, i.e., clarification (T1I1, T2I1), confrontation (T1I2, T2I2) and interpretation (T1I3, T2I3), and used the remaining codes as the conditional behaviors. In a third analysis, the co-therapy (CT) macro-category was taken as the criterion behavior for the three intervention forms (CTI1, CTI2, CTI3) and the remaining codes were taken as the conditional behaviors.

Using the binomial test and the Allison-Liker correction (Allison and Liker, 1982), residuals in lags adjusted from -2 to +2 were calculated [Table 1 shows an example of the adjusted values (RSAJ)]. The analyses were done separately for each of the ten criterion behaviors. Using the GSEQ software, data were entered as .SDS files using the multievent option and then compiled to obtain the .MDS files proposed via the respective. GSQ files were the criterion and conditional behaviors for each analysis and the corresponding lags. The results in .OUT files for each analysis pointed to the existence of various excitatory behavior patterns $(>1.96$, for $\alpha=0.05$ ) (Bakeman and Quera, 1996, 2011).

\section{RESULTS}

Our results are described in four sections: the first reflects turn-taking between the therapists and the children, while the remaining three reflect behavior patterns in relation to use of clarification, confrontation, and interpretation by each therapist separately (T1 and T2) and then together in co-therapy (CT). The 
TABLE 1 | Example of adjusted values (RSAJ) obtained for turn-taking between $\mathrm{T} 1, \mathrm{~T} 2$ and the child subjects.

\begin{tabular}{|c|c|c|c|c|c|c|}
\hline Given: & T1 & T2 & P1 & P2 & P3 & P4 \\
\hline \multicolumn{7}{|l|}{-1} \\
\hline $\mathrm{T} 1$ & -21.58 & 7.15 & 6.29 & 6.61 & 2.24 & 4.95 \\
\hline $\mathrm{T} 2$ & 9.72 & -28.75 & 12.24 & 2.82 & 7.83 & 4.97 \\
\hline P1 & 2.61 & 15.15 & -14.46 & -4.35 & -5.58 & 0.2 \\
\hline P2 & 6.09 & 2.72 & -3.43 & -1.64 & -2.66 & -4.91 \\
\hline P3 & 4.83 & 8.91 & -7.02 & -3.34 & -3.82 & -5.58 \\
\hline P4 & 3.7 & 4.01 & -0.07 & -3.98 & -2.51 & -6.13 \\
\hline \multicolumn{7}{|l|}{0} \\
\hline T1 & 77.78 & -31.29 & -21.75 & -11.3 & -14.25 & -14.94 \\
\hline $\mathrm{T} 2$ & -31.29 & 77.78 & -25.14 & -13.06 & -16.47 & -17.27 \\
\hline P1 & -21.75 & -25.14 & 77.78 & -9.08 & -11.45 & -12.01 \\
\hline P2 & -11.3 & -13.06 & -9.08 & 77.78 & -5.95 & -6.24 \\
\hline P3 & -14.25 & -16.47 & -11.45 & -5.95 & 77.78 & -7.86 \\
\hline P4 & -14.94 & -17.27 & -12.01 & -6.24 & -7.86 & 77.78 \\
\hline \multicolumn{7}{|l|}{1} \\
\hline $\mathrm{T} 1$ & -21.58 & 9.72 & 2.61 & 6.09 & 4.83 & 3.7 \\
\hline $\mathrm{T} 2$ & 7.15 & -28.75 & 15.15 & 2.72 & 8.91 & 4.01 \\
\hline P1 & 6.29 & 12.24 & -14.46 & -3.43 & -7.02 & -0.07 \\
\hline P2 & 6.61 & 2.82 & -4.35 & -1.64 & -3.34 & -3.98 \\
\hline P3 & 2.24 & 7.83 & -5.58 & -2.66 & -3.82 & -2.51 \\
\hline P4 & 4.95 & 4.97 & 0.2 & -4.91 & -5.58 & -6.13 \\
\hline
\end{tabular}

See Figure 4 for a pattern formed from significant results, with values $>1.96$, for $\alpha=0.05$.

\begin{tabular}{|c|c|c|}
\hline-1 & 0 & 1 \\
\hline $\mathrm{T} 2$ & & $\mathrm{~T} 2$ \\
\hline Participants & & Participants \\
\hline $\mathrm{T} 1$ & & $\mathrm{~T} 1$ \\
\hline Participants & & Participants \\
\hline $\mathrm{T} 1$ & & $\mathrm{~T} 1$ \\
\hline $\mathrm{T} 2$ & & $\mathrm{~T} 2$ \\
\hline
\end{tabular}

FIGURE 4 | Results for significant behavior patterns corresponding to turn-taking by therapists T1 and T2 and child participants P1, P2, P3, and P4.

analysis yielded ten distinct interactive behavior patterns between lags -1 and +1 responding to the question: what precedes and what succeeds therapeutic interventions?

\section{Relationships Between Separate Turn-Taking by T1 and T2 and the Children as a Group}

This first set of patterns with arrows, as shown in Figure 4, point to clear symmetry and reciprocity between T1, T2 and the children. This suggests that communication in the group is fluid and that each person is stimulated by the others to participate.

\section{Relationships Between T1 Turn-Taking Interventions Using Clarification, Confrontation, and Interpretation and T2, P1, P2, P3, and P4 Turn-Taking}

The second set of results, depicted in Figure 5, points to differing behavior patterns. In the first pattern, we see how the clarification intervention by $\mathrm{T} 1$ arises after the same kind of intervention by $\mathrm{T} 2$ or after a brief response by one of the children (P2 B1). These interventions generate short responses (B1, B3) by two other children (P2, P4).

The use pattern of confrontation by $\mathrm{T} 1$ is this time much more complex. T1 confrontations follow T2 interpretation interventions (T2 I3) or involuntary behaviors, such as a cough or sneeze (T2 S2), and lead to clarification (I1) and confrontation (I2) interventions by T2. Regarding the children, we see that P1 stimulates T1 with brief interventions (B1) or follow-ups to the conversation (R3), P2 uses non-verbal resources (C1, C3, and S2) and verbal follow-ups to the conversation (R3), whereas P4 laughs. After the therapist has intervened, one of the children (P2) responds with non-verbal approval gestures (C3). The pattern also reflects the possibility of a response in the form of silence (S1) or of a comment regarding the game (M1).

In relation to $\mathrm{T} 1$ interpretations, we also see that these follow interpretation interventions (I3) or laughs (S3) by T2 and, in turn, generate confrontation (I2) and interpretation (I3) interventions. As for the children, of note is humor (S3), short answers (R1) and comments regarding the game (M1) by P3 or involuntary reflexes, such as coughs or sneezes (S2) by P4 prior to the interpretation by T1. A posteriori, the interpretation generates brief expressions of disagreement or doubt (B2) in two of the children (P1 and P4) and interruptions (R2) by another child (P3).

Figure 6 shows an example of a communicative behavior pattern in the use of confrontation by $\mathrm{T} 1$.

\section{Relationships Between T2 Turn-Taking Interventions Using Clarification, Confrontation, and Interpretation and T2, P1, P2, P3, and P4 Turn-Taking}

This third set of results, depicted in Figure 7, is even more complex that the previous set. In the first pattern we see how the clarification intervention (I1) by T2 follows the clarification intervention (I2) by $\mathrm{T} 1$ or a brief response (B1), non-verbal response (C3) or coughing or sneezing (S2) by the children (P2, P3, P4, respectively). T2 clarification interventions generate coughing or sneezing (P2 S2), very short responses or verbal agreement (P3 B1), silence, or comments regarding the game.

As for confrontations (I2) by T2, these follow interpretation or laughter by T1. A priori of the confrontation intervention, the children (P1) briefly express agreement (B1) or doubt (B2), or respond non-verbally, defensively or with laughter (P2), or express their collaboration with the conversation (P3). The confrontational interventions by $\mathrm{T} 2$ generate short responses, positive answers or interruptions by $\mathrm{P} 1$, collaborative 


\begin{tabular}{|c|c|c|c|c|}
\hline-2 & -1 & 0 & 1 & 2 \\
\hline P1 R3 & T2 I1 & P2 B1 B3 & $\mathrm{X}$ \\
\hline
\end{tabular}

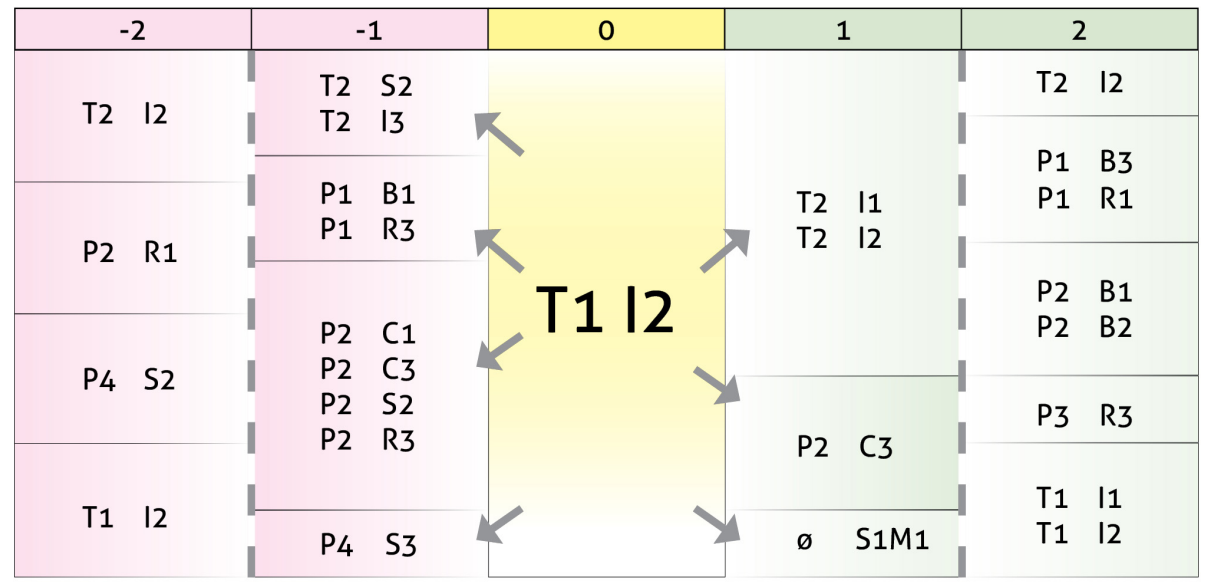

\begin{tabular}{|c|c|c|c|c|c|c|c|}
\hline-2 & \multicolumn{2}{|c|}{-1} & 0 & \multicolumn{2}{|c|}{1} & \multicolumn{2}{|c|}{2} \\
\hline P3 R1 & $\begin{array}{l}\mathrm{T} 2 \\
\mathrm{~T} 2\end{array}$ & $\begin{array}{l}\text { S3 } \\
13\end{array}$ & & $\begin{array}{l}\mathrm{T} 2 \\
\mathrm{~T} 2\end{array}$ & $\begin{array}{l}12 \\
13\end{array}$ & $\mathrm{~T} 2$ & 13 \\
\hline $\begin{array}{ll}\text { P4 } & \text { B2 } \\
\text { P4 } & \text { R1 }\end{array}$ & $\begin{array}{l}\text { P3 } \\
\text { P3 } \\
\text { P3 }\end{array}$ & $\begin{array}{l}\text { S3 } \\
\text { R1 } \\
\text { M1 }\end{array}$ & & $\begin{array}{l}\mathrm{P} 1 \\
\mathrm{Pz}\end{array}$ & B2 & $\begin{array}{l}\text { P3 } \\
\text { P3 }\end{array}$ & $\begin{array}{l}\text { C2 } \\
\text { S3 }\end{array}$ \\
\hline T1 I3 & P4 & S2 & & P4 & B2 & T1 & 13 \\
\hline
\end{tabular}

FIGURE 5 | Results in the form of behavior patterns for interactions between turn-taking interventions by therapist T1 as the focal subject, using clarification (11), confrontation (I2), and interpretation (I3), and turn-taking by therapist T2 and child participants P1, P2, P3, and P4.

\begin{tabular}{|c|l|c|c|c|}
\hline Turn & \multicolumn{1}{|c|}{ Text } & Group & Sibling ASD & Play \\
\hline P2 & P2 shrugs his shoulders and hands in doubt. & C1 & & \\
\hline T1 & T1: What happened if the light was on? & I2 & & \\
\hline$\varnothing$ & T2 looks at the camera and moves the boxes of materials closer to his side. & S1 & & M1 \\
\hline
\end{tabular}

FIGURE 6 | T1 - Significant pattern example.

responses by $\mathrm{P} 3$, coughing or sneezing by $\mathrm{P} 4$ or silence in the whole group.

In relation to the children, the interpretations of $\mathrm{T} 2$ arise from brief expressions of gratitude or collaborative interventions by one child (P1), interruptions by another child (P4) and a non-verbal response by yet another child that stimulates laughter (P2). The interpretations of T2 stimulate interpretation (I3) or confrontation (I2) interventions, and also coughing or sneezing (S2) by T1 and laughter or other sounds reflecting humor in $\mathrm{P} 2$.
Figure 8 shows an example of a communicative behavior pattern in the use of clarification by $\mathrm{T} 2$.

\section{Relationships Between CT Turn-Taking Interventions Using Clarification, Confrontation, and Interpretation and P1, P2, P3, and P4 Turn-Taking}

This final set of results shows that when T1 and T2 are grouped together (i.e., CT), communicative patterns are simplified 


\begin{tabular}{|c|c|c|c|c|c|}
\hline-2 & -1 & 0 & & $L$ & 2 \\
\hline T2 12 & T1 I2 & & & S2 & \multirow{2}{*}{$\begin{array}{ll}\text { P2 } & \text { C2 } \\
\text { P2 } & \text { R3 }\end{array}$} \\
\hline P1 R2 & P2 B1 & & \multirow{2}{*}{\multicolumn{2}{|c|}{ P3 B1 }} & \\
\hline P1 R3 & P3 C3 & & & & \\
\hline P2 B1 & P4 S2 & & $\varnothing$ & S1M1 & \\
\hline
\end{tabular}

\begin{tabular}{|c|c|c|c|c|}
\hline-2 & -1 & 0 & 1 & 2 \\
\hline T1 I2 & $\begin{array}{lll}\mathrm{T} 1 & \mathrm{S3} \\
\mathrm{T} 1 & \mathrm{I}\end{array}$ & & $\begin{array}{ll}\text { P1 } & \text { B1 } \\
\text { P1 } & \text { B3 } \\
P 1 & R 2\end{array}$ & $\begin{array}{ll}T 1 & 12 \\
\text { T1 } & 13\end{array}$ \\
\hline T2 I2 & $\begin{array}{ll}\text { P1 } & \text { B1 } \\
\text { P1 } & \text { B2 }\end{array}$ & & P3 R3 & $\begin{array}{ll}\text { T2 } & 11 \\
\text { T2 } & \text { I2 }\end{array}$ \\
\hline 1213 & $\begin{array}{ll}\text { P2 } & \text { C1 } \\
\text { P2 } & \text { S3 } \\
\text { P2 } & \text { R2 }\end{array}$ & & P4 S2 & $\begin{array}{ll}\text { P2 } & \text { C3 } \\
\text { P2 } & \text { B1 } \\
\text { P2 } & \text { B2 }\end{array}$ \\
\hline P2 R1 & P3 R3 & & ø S1 & P3 B3 \\
\hline
\end{tabular}

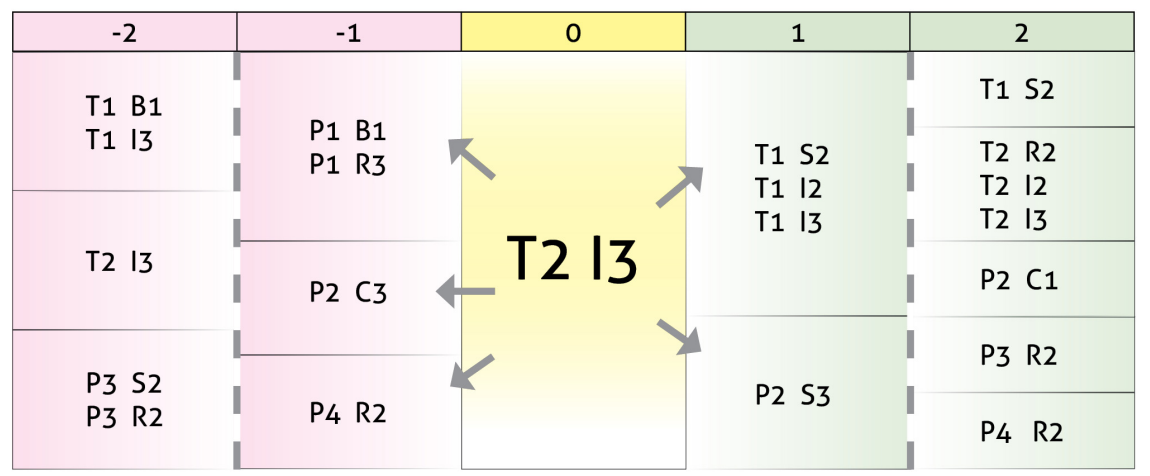

FIGURE 7 | Results in the form of behavior patterns for interactions between turn-taking interventions by therapist T2 as the focal subject, using clarification (11), confrontation (I2), and interpretation (I3), and turn-taking by therapist T1 and child participants P1, P2, P3, and P4.

\begin{tabular}{|c|l|c|c|c|}
\hline Turn & \multicolumn{1}{|c|}{ Text } & Group & Sibling ASD & Play \\
\hline T2 & $\begin{array}{l}\text { It might be what you said P3, that one of the difficulties your } \\
\text { sister might have is that it's difficult to play with her, so maybe } \\
\text { it's hard to figure out how to play with her. }\end{array}$ & I1 & H2 & \\
\hline P3 & Yes, because if she hooks up to something. & $\mathrm{R} 3$ & $\mathrm{H} 2$ & \\
\hline T2 & And you don't find her. & $\mathrm{I}$ & $\mathrm{R} 3$ & $\mathrm{H} 2$ \\
\hline P3 & And there's noone who can get her out of there. & $\mathrm{I}$ & \\
\hline T2 & $\begin{array}{l}\text { Does this happen with your sister P4? Is it hard for your sister to } \\
\text { play? }\end{array}$ & $\mathrm{S} 1$ & & \\
\hline$\varnothing$ & At this point there's 3 seconds of silence. & & \\
\hline
\end{tabular}

FIGURE 8 | T2 - Significant pattern example. 


\begin{tabular}{|c|c|c|c|c|}
\hline-2 & -1 & 0 & 1 & 2 \\
\hline P1 R3 & P1 R1 & P3 B1 & P4 R3 \\
\hline P4 B3 & CT S3 CT | 11 P3 B2 & P4 R2 \\
P4 R3 & P4 R3 & CT B3 \\
\hline
\end{tabular}

\begin{tabular}{|c|c|c|c|c|}
\hline-2 & -1 & 0 & 1 & 2 \\
\hline P2 R1 & P1 B2 & & P1 B3 \\
\hline CT 12 & P2 C1 & & P2 B2 \\
\hline
\end{tabular}

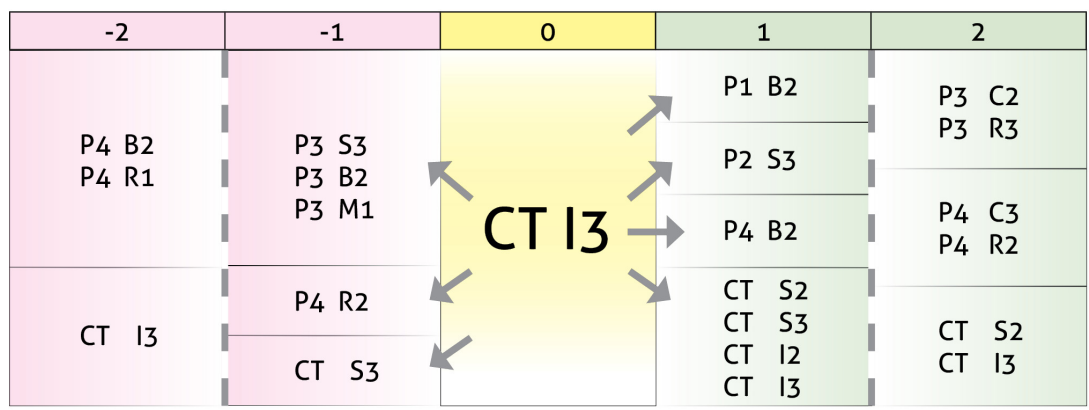

FIGURE 9 | Results in the form of behavior patterns for interactions between turn-taking interventions by the therapists together (CT) as the focal subject, using clarification (11), confrontation (I2), and interpretation (I3), and turn-taking by child participants P1, P2, P3, and P4 .

\begin{tabular}{|c|l|c|c|c|}
\hline Turn & \multicolumn{1}{|c|}{ Text } & Group & Sibling ASD & Play \\
\hline P2 & Shrugs shouders and raises hand to signal doubt. & C1 & \\
\hline T1 o T2 = CT & And what happened if the light was turned on? & $\mathbf{1 2}$ & \\
\hline$\varnothing$ & $\begin{array}{l}\text { T2 looks in the direction of the video camera and sets the boxes } \\
\text { of play materials to one side. }\end{array}$ & S1 & & \\
\hline
\end{tabular}

FIGURE 10 | CT - Significant pattern example.

somewhat, as shown in Figure 9. The first detected pattern is clarification interventions following repeated questions by one child (P1 R1) or laughter or other sounds reflecting humor by the therapists, generating brief assent (B1) or doubt (B2) interventions in another child (P3) or interruptions (R2) or interventions that foster progress (R3) in yet another child (P4).

When the focal subject is $\mathrm{CT}$, confrontation interventions arise after non-verbal responses by $\mathrm{P} 2$ or brief interventions expressing doubt or disagreement by two of the children (P1, P2), generating silence in the group.

Finally, CT interpretation interventions arise after laughter or other sounds reflecting humor in one of the children or the therapists (P3, CT), or brief interventions expressing doubt or disagreement (B2) by one of the children (P3) or interruptions (by $\mathrm{P} 4)$. These interpretations generate other brief interventions expressing doubt or disagreement $(\mathrm{P} 1, \mathrm{P} 4)$, laughter $(\mathrm{P} 2, \mathrm{CT})$ or other confrontation interventions by the therapists (CT).
Figure 10 shows an example of a communicative behavior pattern in CT use of confrontation.

\section{DISCUSSION}

The intervention macro-category was designed as a resource and as a means of communication for psychoanalytical therapists T1 and T2. Unlike the other categories, interventions introduce new variables and new emotional experiences and help to develop new mental models. The changes seen in the children were the result of the attitudes and verbal interventions of the therapists, whether clarification (I1), confrontation (I2), or interpretation (I3).

In the group, both therapists perform clarification after a brief communication (body or sound). As the therapists do not introduce feelings or ideas that the children have not expressed, these continue with a similar discourse in the form of a brief 
response, some sound or silence, followed by manipulation of the material. Given its simplicity and neutrality, this intervention generates confidence and helps improve connections between participants (Coderch, 2009).

Confrontation arises when thoughts are explored in depth (Ferro and Civitarese, 2016). In the group, this type of intervention occurs after brief, body and sound responses, as well as after responses of a more relational nature. Since the therapist highlights omitted aspects, the response is mostly silence, in some cases accompanied by manipulation of the material, by a brief communication (body or sound) and, occasionally, by a more relational tracking response. To a lesser or greater extent, the response is directive. The fact that the main objective may be to facilitate the transition from clarification to interpretation would explain a downward tendency during the group session.

Confrontation helps children overcome their difficulties in expressing themselves. It also facilitates clarification and interpretation interventions (Lichtenberg, 2016). Interpretation is a basic psychoanalytic instrument. To interpret is to explain the unconscious meaning of statements to patients. In the group, interpretation interventions are also represented after brief, body, sound, and relational communications. However, they add to the sequence of material and play, through which therapists inform children of unconscious mental processes that direct and condition their relationships with others. Subsequent responses are usually given by the therapists themselves or, briefly, by the children.

The therapist's efforts focus on bringing the patient to an understanding of how to balance their inner fantasies with influences from the external world.

The emergence of behavioral patterns of silence or of responses that reflect collaboration or dissatisfaction in the children in response to the interventions of the therapists is consistent with results obtained in previous research on the role of the psychoanalytic therapist in group sessions (AriasPujol and Anguera, 2004, 2005) and in individual sessions (Arias-Pujol et al., 2015).

In our sequential analysis it was found that $\mathrm{T} 1$ activates clarification and confrontation interventions by T2 but does not follow up on these interventions. The opposite happens in the interpretation interventions, where $\mathrm{T} 1$ does not activate $\mathrm{T} 2$ interventions, but does follow up. T2 activates all the three types of interventions by $\mathrm{T} 1$ and follows up on confrontation and interpretation interventions.

Both therapists are women. T1 (the older therapist) seems to assume a greater role in containment, tolerance, and follow-up. The younger T2 seems to play a role that is more activating, verbal and available (Kosch and Reiner, 1984). As noted in the results, therapeutic interventions present significant sequences in the response patterns that precede and succeed them.

The co-therapy (CT) analysis, more global than the analysis of individual relationships within the group, is characterized by more general aspects and issues reflecting the group as a whole. Along these lines, it can be observed that in the CT clarification intervention, $\mathrm{P} 1$ is hidden in previous analyses of this category, and, at the same time, the leadership of the other children is obscured. While the subsequent responses are similar to those of the therapists in isolation, there is no room for the silence represented above.

In the confrontation, the two protagonists of separate interventions by the therapists stand out, but therapists conceal what the other children express and leave silence evident. In this case, if the game is not followed up, then this is the only possible response.

Interpretation implies deeper intervention. The cotherapeutic result helps protect the children, since previous and subsequent follow-ups to the interpretation intervention take place between the therapists themselves (Blum, 2016). Thus, T2 activates T1's interpretation and follows up, and T1 activates T2's interpretation and follows up.

These functions do not follow a rule, nor are they permanent. The therapists adapt them to the requirements of the children and complement them in their interventions. Noteworthy is the sum of the attitudes of T1 and T2 in their co-therapeutic work. The fact that they share a theoretical framework and have experience of working together boosts their expertise in creating a facilitating space and in allowing interactions through dialog and play (Bridbord and DeLucia-Waack, 2011). However, we consider that one of the most valuable aspects of this kind of group is the possibility of representing a certain "family model," where therapists are representatives of adults and of children as siblings. Scheidlinger (1974) specifies the need for group members to establish wellbeing regarding the mother (therapists), as a powerful force of identification and connection for the group as a whole.

Of course, there is no differentiation of functions other than those determined by the personal and professional characteristics of each therapist; however, alternating between different functions means they participate in the transference process.

As observed in our results, analyzing the profiles of the therapeutic partners (co-therapists) draws attention to children and responses not observed in the individual analyses of each therapist's interventions.

The results also show that children speak little of their siblings with autism and participate in the sessions spontaneously with all kinds of interventions (liking, disliking, laughter, play, etc.). The communicative richness evident in their behavior patterns reinforces the importance of offering this type of intervention for children with ASD-Sibs (Shivers et al., 2018). The support group helps them think about and of themselves and facilitates their development of a differentiated identity (Fieschi et al., 2011; Centre Educatiu i Terapèutic Carrilet, Alcácer et al., 2013; Venturella et al., 2014).

\section{CONCLUSION}

In addition to our sequential study of the interventions, we were able to observe parallels and interwoven relationships for the two therapists, who complement each other in the direction in which their interventions are intended. Basic aspects of cotherapy include shared impressions, continuous exchanges and integrated countertransference aspects (Cabré, 2002). As noted by Scheidlinger (2005), most group therapists tend to adhere to a 
pluralistic-integrative orientation that appears to be suited to the complexity of individual and group-level manifestations.

A limitation of our study is the fact that results cannot be generalized, given the small size of our sample, both in terms of the number of sessions and the variety of attitudes. Rather, the group should be considered as a unique case analyzed in depth in terms of individual processes.

The methodological characteristics used are highly appropriate for a study of group processes and human interactions (Anguera and Hernández, 2015). However, the complexity and diversity of behaviors to be observed meant we were unable to use a standard instrument. Therefore, a great deal of time was devoted to preparing a tailormade instrument, based exclusively on the profile of the studied group. Our experience suggests that, as proposed by Breeskin (2013), it would be of great interest to broaden the theoretical foundations of co-therapy, as, with further monitoring and evaluation, other groups may benefit from the developed ad hoc instrument and so evolve to new lines of research.

\section{ETHICS STATEMENT}

This study was carried out in accordance with the recommendations of "Comitè d'Ètica de la Recerca (CER-URL)" with written informed consent from all subjects. All subjects gave written informed consent in accordance with the Declaration of

\section{REFERENCES}

Allison, P. D., and Liker, J. K. (1982). Analyzing sequential categorical data on dyadic interaction: a comment on Gottman. Psychol. Bull. 91, 393-403. doi: 10.1037//0033-2909.91.2.393

Angell, M. E., Meadan, H., and Stoner, J. B. (2012). Experiences of siblings of individuals with autism spectrum disorders. Autism Res. Treat. 2012:949586. doi: 10.1155/2012/949586

Anguera, M. T. (1997). "Methodological advances in the assessment of correctional programmes," in Advances in Psychology and Law: International Contributions, eds S. Redondo, V. Garrido, J. Pérez, and R. Barberet, (Berlin: De Gruyter), 465-477.

Anguera, M. T. (2003). "Observational methods (General)," in Encyclopedia of Psychological Assessment, Vol. 2, ed. R. Fernández-Ballesteros, (London: Sage), 632-637.

Anguera, M. T., Blanco, A., Hernández, A., and Losada, J. L. (2011). Diseños observacionales: ajuste y aplicación en psicología del deporte [Observational designs: their suitability and application in sports psychology]. Cuadernos de Psicología del Deporte 11, 63-76.

Anguera, M. T., Blanco, A., and Losada, J. L. (2001). Diseños observacionales, cuestión clave en el proceso de la metodología observacional. [Observational designs, a key issue in the process of Observational Methodology]. Metodología de las Ciencias del Comportamiento 3, 135-161.

Anguera, M. T., and Hernández, A. (2015). Avances en estudios observacionales de ciencias del deporte desde los mixed methods. [Advances in observational studies of sports science from the mixed methods]. Cuadernos de Psicología del Deporte 16, 17-30.

Anguera, M. T., and Izquierdo, C. (2006). "Methodological approaches in human communication. From complexity of situation to data analysis," in From Communication to Presence. Cognition, Emotions and Culture towards the Ultimate Communicative Experience, eds G. Riva, M. T. Anguera, B. K. Wiederhold, and F. Mantovani, (Amsterdam: IOS Press), 203-222.
Helsinki. The protocol was approved by the "Comitè d'Ètica de la Recerca (CER-URL).”

\section{AUTHOR CONTRIBUTIONS}

MV developed the project and performed the sequential analysis. $\mathrm{VC}$ and XC contributed to the documenting and writing of the manuscript. EA-P supervised the project, designed the study, developed the methodology, and drafted the manuscript.

\section{FUNDING}

This research was supported by the Catalan government under Grant 2017 SGR 876 awarded to the project Grup de Recerca de Parella i Família (GRPF).

\section{ACKNOWLEDGMENTS}

We thank our colleagues in Carrilet for their help and suggestions, especially the psychotherapists, Elena Fieschi and Núria Farrés, for their commitment and generosity. We also thank the children in the group and their families, without whom this study would not have been possible. We also gratefully acknowledge the support of Ramon Llull University (PGRiD of FPCEE Blanquerna).

Anguera, M. T., Magnusson, M. S., and Jonsson, G. K. (2007). Instrumentos no estándar [Non- standard instruments]. Avances en Medición 5, 63-82.

Anguera, M. T., Portell, M., Chacón-Moscoso, S., and Sanduvete-Chaves, S. (2018). Indirect observation in everyday contexts: concepts and methodological guidelines within a mixed methods framework. Front. Psychol. 9:13. doi: 10. 3389/fpsyg.2018.00013

Arias-Pujol, E. (2011). Metodología observacional e investigación del proceso grupal. [Observational Methodology and Group Process Research]. Teoría y Práctica Grupoanalítica 1, 435-448.

Arias-Pujol, E., and Anguera, M. T. (2004). Detección de patrones de conducta comunicativa en un grupo terapéutico de adolescentes [Detection of communicative behavior patterns in an adolescent group therapy group]. Acción Psicológica 3, 199-206. doi: 10.5944/ap. 3.3.513

Arias-Pujol, E., and Anguera, M. T. (2005). Análisis de la comunicación en un grupo terapéutico de adolescentes: estudio diacrónico [Analysis of communication in a therapy group of adolescents: a diachronic study]. Revista de Psicopatología y Salud Mental, M 1, 25-36.

Arias-Pujol, E., and Anguera, M. T. (2017). Observation of interactions in adolescent group therapy: a mixed methods study. Front. Psychol. 8:1188. doi: 10.3389/fpsyg.2017.01188

Arias-Pujol, E., Fieschi, C., Castelló, J., Miralbell, A., Soldevila, E., SánchezCaroz, E., et al. (2015). Efectos de la imitación en la interacción social recíproca en un niño con trastorno del espectro autista grave [Effects of imitation in reciprocal social interaction in a child with severe ASD]. Revista de Psicopatología y Salud Mental del Niño y del Adolescente $25,9-20$.

Bakeman, R. (1978). "Untangling streams of behavior: sequential analysis of observation data," in Observing Behavior, Vol. 2: Data Collection and Analysis Methods, ed. G. P. Sackett, (Baltimore, MD: University of Park Press), 63-78.

Bakeman, R., and Gottman, J. M. (1989). Observación de la Interacción: Introducción al Análisis Secuencial [Observing the interaction: Introduction to Sequential Analysis]. Madrid: Morata. 
Bakeman, R., and Quera, V. (1996). Análisis de la Interacción. Análisis Secuencial con SDIS y GSEQ [Analyzing Interaction: Sequential Analysis with SDIS and GSEQ]. Madrid: Ra-Ma.

Bakeman, R., and Quera, V. (2011). Sequential Analysis and Observational Methods for the Behavioral Sciences. Cambridge: Cambridge University Press.

Bazeley, P. (2012). Integrative analysis strategies for mixed data sources. Am. Behav. Sci. 56, 814-828. doi: 10.1177/0002764211426330

Bazeley, P. (2017). A mixed methods way of thinking and doing: integration of diverse perspectives in practice. Aoyama J. Int. Stud. 4, 17-28.

Ben-Itzchak, E., Nachshon, N., and Zachor, D. A. (2018). Having siblings is associated with better social functioning in autism spectrum disorder. J. Abnorm. Child Psychol. 47, 921-931. doi: 10.1007/s10802-018-0473-z

Bergman, M. M. (2010). On concepts and paradigms in mixed methods research. J. Mix. Methods Res. 4, 171-175. doi: 10.1177/155868981037 6950

Blum, H. (2016). Interpretation and contemporary reinterpretation. Psychoanal. Inq. 36, 40-51. doi: 10.1080/07351690.2016.1112220

Breeskin, J. (2013). The Co-Therapist Model in Group. Society of Group Psychology and Group Psychotherapy. Available at: http://www.apadivisions.org/division49/publications/newsletter/group-psychologist/2013/04/co-therapist.aspx? _ga $=1.121842755 .932961816 .1458676062$ zs (accessed November 8, 2017).

Bridbord, K., and DeLucia-Waack, J. (2011). Personality, leadership style, and theoretical orientation as predictors of group co-leadership satisfaction. J. Spec. Group Work 36, 202-221. doi: 10.1080/01933922.2011.578117

Bryman, A. (2007). Barriers to integrating qualitative and quantitative research. J. Mix. Methods Res. 1, 8-22. doi: 10.1177/2345678906290531

Cabré, V. (2002). Escenoterapia. Dramatización Terapéutica en Grupo [Scene Therapy. Therapeutic Dramatization in group]. Barcelona: Paidós.

Cassel, T. D., Messinger, D. S., Ibanez, L. V., Haltigan, J. D., Acosta, S. I., and Buchman, A. C. (2007). Early social and emotional communication in the infant siblings of children with autism spectrum disorders: an examination of the broad phenotype. J. Autism Dev. Disord. 37, 122-132. doi: 10.1007/s10803-0060337-1

Centre Educatiu i Terapèutic Carrilet, Alcácer, B., Farrés, N., González, S., Mestres, M., Monreal, N., et al. (2013). Comprensión y Abordaje Educativo y Terapéutico del TEA. [Dealing with and understanding ASD]. Barcelona: Horsori.

Christon, L. M., and Myers, B. J. (2015). Family-centered care practices in a multidisciplinary sample of pediatric professionals providing autism spectrum disorder services in the United States. Res. Autism Spectr. Disord. 20, 47-57. doi: 10.1016/j.rasd.2015.08.004

Coderch, J. (2009). Teoría y Técnica de la Psicoterapia Psicoanalítica. [Theory and technique of psychoanalytic psychotherapy]. Barcelona: Herder.

Cohen, J. (1960). A coefficient of agreement for nominal scales. Educ. Psychol. Meas. 20, 37-46. doi: 10.1177/001316446002000104

Cohen, J. (1968). Weighted kappa: nominal scale agreement with provision for scaled disagreement of partial credit. Psychol. Bull. 70, 213-220. doi: 10.1037/ h0026256

Creswell, J. W., Plano Clark, V. L., Gutmann, M. L., and Hanson, W. E. (2003). "Advanced mixed methods research designs," in Handbook of Mixed Methods in Social and Behavioral Research, eds A. Tashakkori, and C. Teddlie, (Thousand Oaks, CA: Sage), 209-240.

Del Giacco, L., Salcuni, S., and Anguera, M. T. (2019). The communicative modes analysis system in psychotherapy from mixed methods framework: introducing a new observation system for classifying verbal and nonverbal communication. Front. Psychol. 10:782. doi: 10.3389/fpsyg.2019. 00782

Farrés, N. (2014). Confluència de les Vessants Educativa i Terapèutica per al Treball amb Infants amb TEA: de l'emoció a la Cognició. [Confluence of Educational Aspects and Therapeutic for Work With children With ASD: from Emotion to Cognition]. Desenvolupa: La revista de l'atenció precoç. Available at: http://www.desenvolupa.net/Ultims-articles/Confluencia-de-les-vessantseducativa-i-terapeutica-per-al-treball-amb-infants-amb-TEA-de-1-emocioa-la-cognicio-Nuria-Farres-Marti-06-2014 (accessed November 8, 2017).

Ferraioli, S. J., and Harris, S. L. (2009). The impact of autism on siblings. Soc. Work Ment. Health 8, 41-53.

Ferro, A., and Civitarese, G. (2016). Confrontation in the bionian model of the analytic field. Psychoanal. Inq. 36, 307-322. doi: 10.1080/07351690.2016. 1158060
Fetters, M. D., and Freshwater, D. (2015). The $1+1=3$ integration challenge. J. Mix. Methods Res. 9, 115-117. doi: 10.1177/1558689815581222

Fieschi, E., Farrés, N., and Valls, C. (2011). Pors i Ansietats en un Grup de Germans de nens Autistes. [Fears and Anxieties in a Sibling Group of ASD Children]. Comunicación Presentada en las XXVI Jornadas de la Revista Catalana de Psicoanàlisi. Barcelona: Casa del Mar.

Gabovitch, E. M., and Curtin, C. (2009). Family-centered care for children with autism spectrum disorders: a review. Marriage Fam. Rev. 45, 469-498. doi: 10.1080/01494920903050755

García-Fariña, A., Jiménez-Jiménez, F., and Anguera, M. T. (2018). Observation of communication by physical education teachers: detecting patterns in verbal behavior. Front. Psychol. 9:334. doi: 10.3389/fpsyg.2018.00334

Gimeno, A., Anguera, M. T., Berzosa, A., and Ramírez, L. (2006). Detección de patrones interactivos en la comunicación de familias con hijos adolescentes [Detection of interactive communication patterns in families with adolescent children]. Psicothema 18, 785-790.

Griffith, G. M., Hastings, R. P., and Petalas, M. A. (2014). Brief report: fathers' and mothers' ratings of behavioral and emotional problems in siblings of children with autism spectrum disorder. J. Autism Dev. Disord. 44, 1230-1235. doi: 10.1007/s10803-013-1969-6

Happ, M. B., Dabbs, A. D., Tate, J., Hricik, A., and Erlen, J. (2006). Exemplars of mixed methods data combination and analysis. Nurs. Res. 55(Suppl. 1), S43-S49.

Harris, S. L., and Glasberg, B. A. (2003). Siblings of Children With Autism: A Guide for Families. Bethesda: Woodbine House.

Hastings, R. P. (2003). Behavioral adjustment of siblings of children with autism engaged in applied behavior analysis early intervention programs: the moderating role of social support. J. Autism Dev. Disord. 33, 141-150. doi: 10.1023/A:102298320

Hastings, R. P., and Petalas, M. A. (2014). Self-reported behaviour problems and sibling relationship quality by siblings of children with autism spectrum disorder. Child Care Health Dev. 40, 833-839. doi: 10.1111/cch.12131

Hesse-Biber, S., and Johnson, R. B. (2013). Coming at things differently: future directions of possible engagement with mixed methods research. J. Mix. Methods Res. 7, 103-109. doi: 10.1177/1558689813483987

Hoffman, S., and Laub, B. (2006). Innovative Interventions in Psychotherapy. Florida: Universal Publishers.

Johnson, R. B., Onwuegbuzie, A. J., and Turner, L. A. (2007). Toward a definition of mixed methods research. J. Mix. Methods Res. 1, 112-133. doi: 10.1177/ 1558689806298224

Kosch, S. G., and Reiner, C. A. (1984). The co-therapy relationship: mutuality, agreement and client outcome. J. Contemp. Psychother. 14, 145-157. doi: 10. 1007/bf00946312

Krippendorff, K. (2004). Content Analysis. An Introduction to its Methodology. Thousand Oaks, CA: SAGE.

Krippendorff, K. (2013). Content Analysis. An Introduction to its Methodology, 3rd Edn. Thousand Oaks, CA: Sage.

Lapresa, D., Arana, J., Anguera, M. T., and Garzón, B. (2013). Comparative analysis of the sequentiality using SDIS-GSEQ and THEME: a concrete example in soccer. J. Sports Sci. 31, 1687-1695. doi: 10.1080/02640414.2013.79 6061

Lichtenberg, J. D. (2016). Interpretation revisited. Psychoanal. Inq. 36, 4-13. doi: 10.1080/07351690.2016.1112217

Macks, R. J., and Reeve, R. E. (2007). The adjustment of non-disabled siblings of children with autism. J. Autism Dev. Disord. 37, 1060-1067. doi: 10.1007/ s10803-006-0249-0

Mascha, K., and Boucher, J. (2006). Preliminary investigation of a qualitative method of examining siblings' experiences of living with a child with ASD. Br. J. Dev. Disabil. 52, 19-28. doi: 10.1179/096979506799103659

McHale, S. M., Updegraff, K. A., and Feinberg, M. E. (2016). Siblings of youth with autism spectrum disorders: theoretical perspectives on sibling relationships and individual adjustment. J. Autism Dev. Disord. 46, 589-602. doi: 10.1007/s10803015-2611-6

Meyer, K. A., Ingersoll, B., and Hambrick, D. Z. (2011). Factors influencing adjustment in siblings of children with autism spectrum disorders. Res. Autism Spectr. Disord. 5, 1413-1420. doi: 10.1016/j.rasd.2011.01.027

Onwuegbuzie, A., and Leech, N. (2005). On becoming a pragmatic researcher: the importance of combining quantitative and qualitative research methodologies. 
Int. J. Soc. Res. Methodol. 8, 375-387. doi: 10.1080/1364557050040 2447

Onwuegbuzie, A. J., Hitchcock, J., Natesan, P., and Newman, I. (2018). Using fully integrated thinking to address the $1+1=1$ integration challenge. Int. J. Mult. Res. Approaches 10, 666-678. doi: 10.29034/ijmra.v10n1a43

Petalas, M. A., Hastings, R. P., Nash, S., Reilly, D., and Dowey, A. (2012). The perceptions and experiences of adolescent siblings who have a brother with autism spectrum disorder. J. Intellect. Dev. Disabil. 37, 303-314. doi: 10.3109/ 13668250.2012.734603

Portell, M., Anguera, M. T., Chacón-Moscoso, S., and Sanduvete-Chaves, S. (2015). Guidelines for reporting evaluations based on observational methodology. Psicothema 27, 283-289. doi: 10.7334/psicothema2014.276

Rodríguez-Dorta, M., and Borges, Á (2017). Behavioral patterns in special education. Good teaching practices. Front. Psychol. 8:631. doi: 10.3389/fpsyg. 2017.00631

Roller, B., and Nelson, V. (1996). "Co-therapy," in Comprehensive Group Psychotherapy, 3rd Edn, eds H. I. Kaplan, and B. J. Sadock, (Baltimore, MD: Williams and Wilkins Co), 334-343.

Roustan, M., Izquierdo, C., and Anguera, M. T. (2013). Sequential analysis of an interactive peer support group. Psicothema 25, 396-401. doi: 10.7334/ psicothema2012.93

Sackett, G. P. (1979). "The lag sequential analysis of contingency and cyclicity on behavioral interactional research," in Handbook of Infant Development, ed. J. D. Osofsky, (New York, NY: Wiley), 623-649.

Sackett, G. P. (ed.) (1978). (Observing)Behavior (Vol.2): Data Collection and Analysis Methods. Baltimore: University of Park Press.

Sánchez-Algarra, P., and Anguera, M. T. (2013). Qualitative/quantitative integration in the inductive observational study of interactive behaviour: impact of recording and coding among predominating perspectives. Qual. Quant. 47, 1237-1257. doi: 10.1007/s11135-012-9764-6

Scheidlinger, S. (1974). On the concept of the "mother-group.". Int. J. Group Psychother. 24, 417-428. doi: 10.1080/00207284.1974.11491849

Scheidlinger, S. (2005). Group interventions with traumatized children. Revisited Saul Scheidlinger, Ph.d. Gloria Batkin Kahn, Ed.d. Int. J. Group Psychother. 55, 335-354. doi: 10.1521/ijgp.2005.55.3.335

Shivers, C. M., Deisenroth, L. K., and Taylor, J. L. (2013). Patterns and predictors of anxiety among siblings of children with autism spectrum disorders. J. Autism Dev. Disord. 43, 1336-1346. doi: 10.1007/s10803-0121685-7

Shivers, C. M., Jackson, J. B., and McGregor, C. M. (2018). Functioning among typically developing siblings of individuals with autism spectrum disorder: a meta-analysis. Clin. Child Fam. Psychol. Rev. 22, 172-196. doi: 10.1007/s10567018-0269-2

Sommantico, M. (2016). A couple's unconscious communication: dreams. Br. J. Psychother. 32, 456-474. doi: 10.1111/bjp.12251
Tashakkori, A., and Teddlie, C. (eds) (2010). The Sage Handbook of Mixed Methods in Social and Behavioral Research, 2nd Edn. Thousand Oaks, CA: Sage.

Tsao, L., and McCabe, H. (2010). Why won't he play with me? Facilitating sibling interactions. Young Except. Child. 13, 24-35. doi: 10.1177/1096250610377163

Tsao, L. L., Davenport, R., and Schmiege, C. (2012). Supporting siblings of children with autism spectrum disorders. Early Child. Educ. J. 40, 47-54. doi: 10.1007/ s10643-011-0488-3

Vaimberg, R. (2010). Psicoterapias Tecnológicamente Mediadas (PTM). Estudio de procesos y Microprocesos a Partir de Participación Online. [Technologically Mediated Psychotherapies (PTM). Study of Processes and Microprocesses From Online Participation]. Barcelona: Universidad de Barcelona.

Vaimberg, R. (2012). Psicoterapia de Grupo, Psicoterapia de Grupo Online: Teoría, Técnica e Investigación. [Online Group Psychotherapy: Theory, Technique and Research]. Barcelona: Octaedro.

Venturella, M., Arias-Pujol, E., Cabré, V., Fieschi, E., and Farrés, N. (2015). Investigar la comunicación en el grupo: el desarrollo de un instrumento observacional para un grupo de hermanos de niños con TEA. [Group communication research: the development of an observational instrument for an ASD-sibling group]. Cuadernos de Psiquiatría y Psicoterapia del Niño y del Adolescente 60, 53-59.

Venturella, M., Cabré, V., and Arias-Pujol, E. (2014). Estudio exploratorio sobre la percepción familiar de hermanos de niños autistas: participar o no participar de un grupo de apoyo. [Exploratory study about the family perception of siblings of autistic children: to participate or not to participate in a support group]. Teoría y práctica grupoanalítica $4,291-304$.

Walton, K. M., and Ingersoll, B. R. (2015). Psychosocial adjustment and sibling relationships in siblings of children with autism spectrum disorder: risk and protective factors. J. Autism Dev. Disord. 45, 2764-2778. doi: 10.1007/s10803015-2440-7

Yoder, P., Stone, W. L., Walden, T., and Malesa, E. (2009). Predicting social impairment and ASD diagnosis in younger siblings of children with autism spectrum disorder. J. Autism Dev. Disord. 39, 1381-1391. doi: 10.1007/s10803009-0753-0

Conflict of Interest Statement: The authors declare that the research was conducted in the absence of any commercial or financial relationships that could be construed as a potential conflict of interest.

Copyright (c) 2019 Venturella, Carbonell, Cabré and Arias-Pujol. This is an openaccess article distributed under the terms of the Creative Commons Attribution License (CC BY). The use, distribution or reproduction in other forums is permitted, provided the original author(s) and the copyright owner(s) are credited and that the original publication in this journal is cited, in accordance with accepted academic practice. No use, distribution or reproduction is permitted which does not comply with these terms. 